\title{
Electrooxidation of Iodide Ion at Poly 8-(3-acetylimino-6-methyl-2,4- dioxopyran)-1-aminonaphthalene Modified Electrode in Aqueous Solution
}

\author{
A. A. Hathoot \\ Electrochemistry laboratory, Chemistry Department, Faculty of Science, \\ Menoufia University, Shebin Elkom, Egypt \\ (E-mail: ablahathoot@yahoo.com)
}

RECEIVED JANUARY 1, 2011; REVISED APRIL 21, 2011; ACCEPTED APRIL 27, 2011

\begin{abstract}
Poly 8-(3-acetylimino-6-methyl-2,4-dioxopyran)-1-aminonaphthalene (PAMDAN) films were electrodeposited on platinum electrode $(\mathrm{Pt})$, forming PAMDAN/Pt modified electrode, to study its utility in electrooxidation of iodide ion. The electrooxidation process was investigated by cyclic voltammetry. The effects of different factors $e . g$. scan rate, iodide ion concentration, film thickness and acid concentration have been studied to improve the redox response of PAMDAN/Pt modified electrode during the oxidation process. (doi: 10.5562/cca1843)
\end{abstract}

Keywords: modified electrode, polymer film, conducting polymer, platinum electrode, electrocatalysis, electrooxidation, iodine

\section{INTRODUCTION}

The use of bare electrodes for electrochemical oxidation and detection has a number of limitations, such as low sensitivity and reproducibility, slow electron transfer reaction, low stability over a wide range of solution composition and high overpotential at which the electron transfer process occurs. Moreover, the bare electrodes very often suffer from the fouling effect due to the accumulation of oxidized product on the electrode surface, which results in rather poor selectivity and sensitivity. ${ }^{1,2}$ The chemical modifications of inert substrate electrodes with redox active thin films offer significant advantages in the design and development of electrochemical sensors. In operation, the redox active sites shuttle electrons between the analyte and the electrodes with significant reduction in activation overpotential. A further advantage of the chemically modified electrodes is that they are less prone to surface fouling and oxide formation compared to inert substrate electrodes. A wide variety of compounds has been used as electron transfer mediators for modification of electrode surfaces with various procedures. ${ }^{3}$

Electrocatalysis is the science of modifying the overall rates of electrochemical reactions so that selectivity, yield and efficiency are maximized. Modified electrodes are widely used in the field of electrocatalysis. ${ }^{4-8}$ One of the most important electrode modification techniques involves the formation of an electro catalytic system on the electrode surface in which redox species capable of undergoing a rapid and reversible electrode reaction are incorporated. These electrodes reduce the over potential required for either oxidation or reduction of compounds. Among the modified electrodes which exhibit electro catalytic properties are conducting polymers. Conducting polymers, e.g. polyaniline and its derivatives were examined as a mediators in several redox reactions soon after the discovery of its conductivity. $^{9}$

Iodine is an essential trace element playing an important role in mental development growth and basic metabolism. ${ }^{10}$ The lack of thyroid hormone causes poor mental and physical development in children and enlargement of the thyroid (gotire) in adults. There is a vital importance of iodide in environment, medicine and industry. ${ }^{11,12}$

In the anodic oxidation of iodide on $\mathrm{Pt}$ it was observed that, the anodic current may suddenly drop above a certain concentration of iodide. In this case the formation of a thick iodine film on the electrode, which impedes the passage and the oxidation of iodide, was observed. Detailed studies on the formation, thickness, properties, growth and dissolution of the iodine film during the anodic oxidation of iodide have been performed. ${ }^{13-17}$ Anodic oxidation of iodide is consecutive process; it consists of a series of elementary steps, such as the diffusion of iodide to the electrode, the discharge of iodide ions at the electrode, the complexing of the 
product iodine with $\mathrm{I}^{-}$(and $\mathrm{I}_{3}^{-}$, etc.), and the diffusion of iodine species from the electrode surface to the bulk solution. $^{18}$

On the polymer-filmed electrode immersed in solution, at least three different interfaces exist: the $\mathrm{Pt} /$ polymer interface, the internal polymer/solution interface in the polymer film and the external polymer/solution interface on the surface of the polymer film. Thus, there are several steps involved in the anodic oxidation of iodide at the polymer anode: (i) iodide ion diffuses from the bulk of the solution to the electrode surface, (ii) it diffuses further through the polymer film onto the inner surface of the polymer and the uncovered surface of the Pt electrode, (iii) it loses electrons to liberate iodine, (iv) an iodine film is formed, (v) iodine is transformed into iodine - iodide complex and is reoxidized and (vi) iodine and triiodide ion diffuses within the polymer but also diffuses out of the polymer surface. Also it was found that the $\mathrm{I}_{3}{ }^{-} / \mathrm{I}^{-}$reaction takes place throughout the film and not at the metal- polymer interface. ${ }^{17}$ On the external surface of the polymer film, a layer of iodine is deposited during an anodic scan.These reaction sites at the external surface of the polymer film for the reduction of iodine species are assigned as the primary reaction sites, where the electrode reaction takes place, as on the bare Pt electrode. On the other hand, the bulk of the polymer film is considered as having a porous nature (e.g. polyaniline and its derivatives). During the anodic potential scan, part of the iodine species is also adsorbed or deposited on the inner surface of the film, which is also subject to reduction during the next cathodic scan. Tang et al. (Ref. 16) suggest that on the inner surface of the poly-aniline film the iodine species react with the poly aniline chains by the formation of electron donor-acceptor (EDA) complex between $\mathrm{I}_{2}$ and the $\mathrm{N}$ atom in the polyaniline chains, and the strong electrostatic attraction between negatively charged $\mathrm{I}_{3}^{-}$and the positively charged $\mathrm{N}$ atom in the polyaniline chains. These reaction sites are denoted as the secondary reaction sites .

The present study is an attempt aimed to present the electro catalytic oxidation of iodine on the poly AMDAN/Pt modified electrode, to discuss the influence of various experimental conditions such as scan rate, film thickness and iodide ion concentration, and to improve the redox response of PAMDAN/Pt modified electrode during the oxidation process

\section{EXPERIMENTAL}

The chemicals, 1,8-diaminonaphthalene, dehydroacetic acid, ethanol, potassium iodide (KI), sulfuric acid $\left(\mathrm{H}_{2} \mathrm{SO}_{4}\right)$ and perchloric acid $\left(\mathrm{HClO}_{4}\right)$, were analytical grade chemicals (Aldrich) and used without further purification. Aqueous solutions were prepared from bidistilled water. Electrochemistry was performed using the EG\&G PAR computer measuring system model 250 and a Hewlett-Packard X-Y recorder model 7440.

Cyclic voltammetry was conducted using a threeelectrode electrolytic cell (Bioanalytical system, model $\mathrm{C}-1 \mathrm{~A})$ in which a platinum disc electrode $(\mathrm{Pt})(3.0 \mathrm{~mm}$ diam.), was used as working electrode, a platinum sheet (area $2 \mathrm{~cm}^{2}$ ) as counter electrode and $\mathrm{Ag} \mid \mathrm{AgCl}$ as reference electrode. All experiments were done at room temperature. AMDAN Schiff base was prepared and characterized previously ${ }^{18,19}$ and its structure is shown in the Scheme 1.<smiles>CC1=CC(=O)C(/C(C)=N/c2cccc3cccc(N)c23)C(=O)O1</smiles>

Scheme 1. 8-(3-acetylimino-6-methyl-2,4 dioxopyran)-1-aminonaphthaline (AMDAN Schiff-base).

Poly AMDAN films were formed on Pt electrode using cyclic voltammetric technique in $0.1 \mathrm{M}$ aqueous solution of $\mathrm{H}_{2} \mathrm{SO}_{4}$ containing $1 \cdot 10^{-3} \mathrm{M}$ of AMDAN monomer. The electrode potential was swept repeatedly in the potential range from -0.2 to $0.8 \mathrm{~V}$, at scan rate of $0.02 \mathrm{~V} \mathrm{~s}^{-1}$, for 15 cycles. $^{20}$ The resulting film electrode was washed by dipping in distilled water and transferred into the test solution. The cyclic voltamogram of poly AMDAN/Pt modified electrode dipped in test solution (AMDAN free) containing $0.1 \mathrm{M} \mathrm{HClO}_{4}$ at scan rate of $0.05 \mathrm{~V} \mathrm{~s}^{-1}$, in potential range between -0.2 and $0.8 \mathrm{~V}$ is shown in Figure 1. The voltamogram presents the redox system of the polymer film, so an oxidation peak appeared at about $+0.24 \mathrm{~V}$ and its cathodic response appear at about $0.19 \mathrm{~V}^{20}$

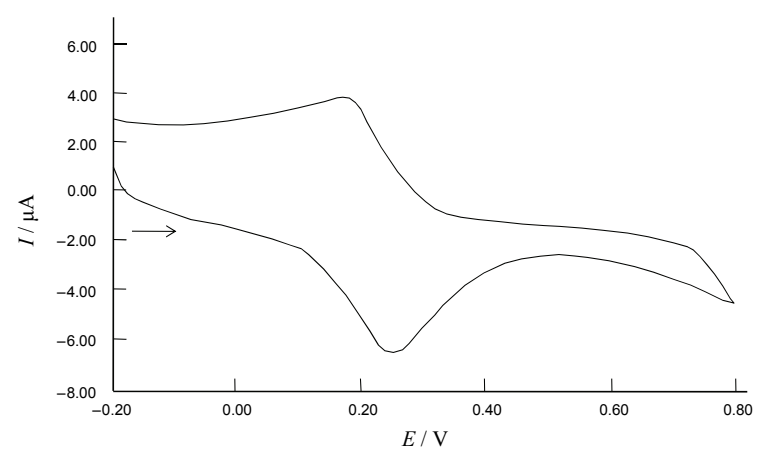

Figure 1. The electrochemical response of PAMDAN/Pt modified electrode in $0.1 \mathrm{M} \mathrm{HClO}_{4}$ aqueous solution at scan rate of $0.05 \mathrm{~V} \mathrm{~s}^{-1}$. The film prepared as in text. 


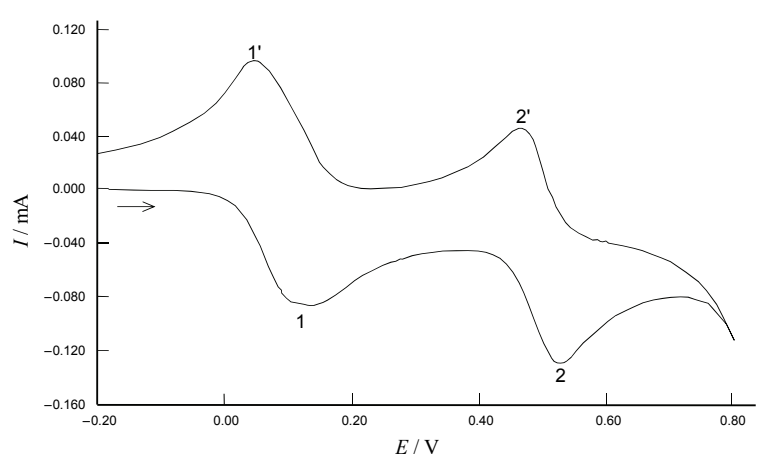

Figure 2. Cyclic voltamogram at the bare Pt electrode in $0.1 \mathrm{M}$ $\mathrm{HClO}_{4}$ containing $0.1 \mathrm{M} \mathrm{KI}$ at $v=50 \mathrm{mV} \mathrm{s}^{-1}$. The starting potential is $-0.2 \mathrm{~V}$ and the initial scan direction is positive. Oxidation current is negative. The oxidation peaks are marked as 1 and 2, while the reduction peaks are marked as 1' and 2'.

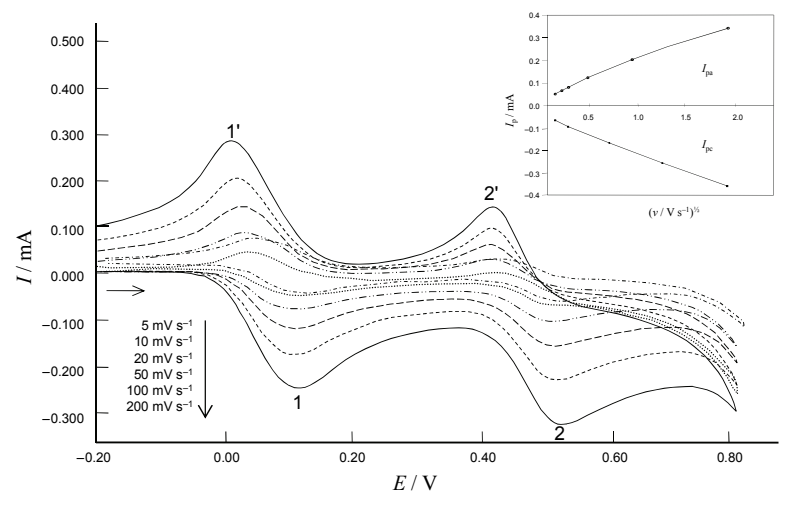

Figure 3. Cyclic voltamograms at the bare Pt electrode in $0.1 \mathrm{M}$ $\mathrm{HClO}_{4}$ containing $0.1 \mathrm{M} \mathrm{KI}$ at different scan rates. $v=5 \mathrm{mV}$ $\mathrm{s}^{-1}$ (line dot line), $10 \mathrm{mV} \mathrm{s}^{-1}$ (broken line), $20 \mathrm{mV} \mathrm{s}^{-1}$ (full line), $50 \mathrm{mV} \mathrm{s}^{-1}$ (dots), $100 \mathrm{mV} \mathrm{s}^{-1}$ (broken line) and $200 \mathrm{mV}$ $\mathrm{s}^{-1}$ (full line). Inset illustrate the dependence of $I_{\mathrm{pa}}, I_{\mathrm{pc}}$ on the square root of scan rate.

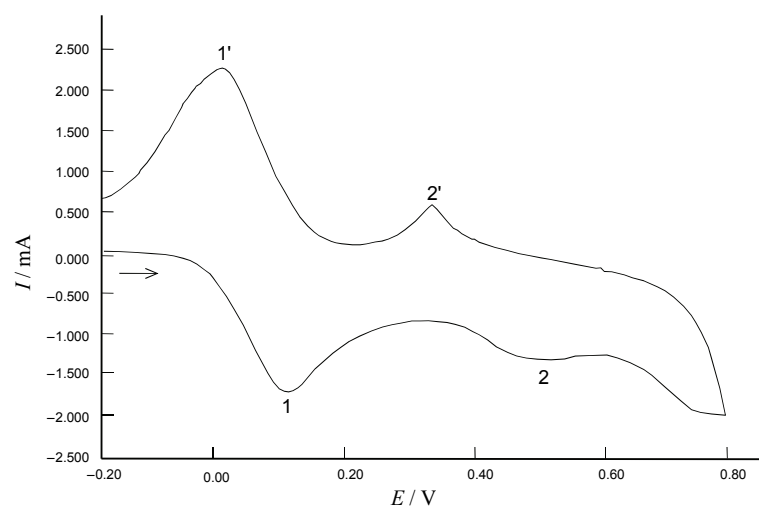

Figure 4. Cyclic voltamogram of the PAMDAN/Pt modified electrode in $0.1 \mathrm{M} \mathrm{HClO}_{4}$ containing $0.1 \mathrm{M} \mathrm{KI}$ at $v=50 \mathrm{mV} \mathrm{s}^{-1}$. The modified electrode was prepared as mentioned in the text.

\section{RESULTS AND DISCUSSION}

\section{Electrochemical Oxidation of Iodide Ion on Bare Pt Electrode}

The redox process of the iodine-iodide couple at $\mathrm{Pt}$ electrode is shown in Figure 2. The cyclic voltamograms at $\mathrm{Pt}$ electrode in $0.1 \mathrm{M}$ solution of $\mathrm{HClO}_{4}$ containing $0.1 \mathrm{M} \mathrm{KI}$, in potential range between -0.2 and $0.8 \mathrm{~V}$ at scan rate of $0.05 \mathrm{~V} \mathrm{~s}^{-1}$ (vs. $\mathrm{Ag} \mid \mathrm{AgCl}$ ), shows two waves. The first anodic peak appears at $0.11 \mathrm{~V}$ and the second one at $0.5 \mathrm{~V}$. The corresponding cathodic peaks appear at $0.032 \mathrm{~V}$ and $0.4 \mathrm{~V}$ for the first and the second peak, respectively, which means that the oxidation process consists of more than one step. They are the oxidation of $\mathrm{I}^{-}$to $\mathrm{I}_{3}^{-}$with the formation of the iodine-iodide complex and the oxidation of iodide and/or triiodide ions in which the iodine film is formed on the electrode surface. ${ }^{16}$

The following reactions may be involved in the oxidation process:

$$
\begin{aligned}
& 2 \mathrm{I}^{-}-2 \mathrm{e}^{-} \rightleftarrows \mathrm{I}_{2} \\
& 3 \mathrm{I}^{-}-2 \mathrm{e}^{-} \rightleftarrows \mathrm{I}_{3}^{-} \\
& 2 \mathrm{I}_{3}^{-}-2 \mathrm{e}^{-} \rightleftarrows 3 \mathrm{I}_{2}
\end{aligned}
$$

The successive oxidation of iodide ions (Equations $1-3$ ) were clearly demonstrated in Figure 2 . The $1^{\text {st }}$ peak may be due to the oxidation of $\mathrm{I}^{-}$to $\mathrm{I}_{3}^{-}$, that is to the formation of the iodine-iodide complex via Equation 2. The $2^{\text {nd }}$ peak corresponds to the oxidation of iodide and/or triiodide ions in which the iodine film is formed on the electrode surface. The dissolution of iodine film takes place according to the following Equation:

$$
\mathrm{I}_{2}+\mathrm{I}^{-} \rightleftarrows \mathrm{I}_{3}^{-}
$$

Equation 4 is a competition reaction for Equation $1 .^{21-23}$

The electrooxidation of iodide ion at different scan rates (from 0.005 to $0.2 \mathrm{~V} \mathrm{~s}^{-1}$ ) is shown in Figure 3 . This Figure illustrates that the redox response of the oxidation of iodide ion depends on the scan rate. The anodic and the cathodic peak currents of the $1^{\text {st }}$ wave are linearly proportional to the square root of scan rate (as shown in the inset), which suggests that the oxidation process is controlled by diffusion. ${ }^{18-20}$

\section{Electrochemical Response of KI on PAMDAN/Pt Modified Electrode}

The voltammetric behavior of iodide ion on PAMDAN/Pt modified electrode was studied using cyclic voltammetry in $0.1 \mathrm{M}$ solution of $\mathrm{HClO}_{4}$ containing $0.1 \mathrm{M} \mathrm{KI}$, 
in potential range between -0.2 and $0.8 \mathrm{~V}$ at scan rate of $0.05 \mathrm{~V} \mathrm{~s}^{-1}$ (vs. $\mathrm{Ag} \mid \mathrm{AgCl}$ ). Figure 4 illustrates that the redox response of iodide ion at modified electrode is affected by the PAMDAN film. The voltamogram consists of two waves, as on the bare Pt electrode, but with some modifications: there is an increase in the current peak of the $1^{\text {st }}$ wave and the decrease of current peak of the $2^{\text {nd }}$ wave, which appears broader. Figure 5 studies the redox response of the iodide ions at modified electrode at different scan rates, from 0.005 to $0.2 \mathrm{~V} \mathrm{~s}^{-1}$. The linear relationship between peak currents of the $1^{\text {st }}$ wave and the square root of the scan rate is shown in the inset of the Figure 5. It suggests that a diffusion-controlled step is involved in the oxidation process at the modified electrode. This is consistent with the so-called deposition-dissolution mechanism for oxidation of iodide to iodine, where a film of iodine is deposited on the electrode surface. Figure 5 illustrates also that at sufficiently slow scan rates a new peak at $0.68 \mathrm{~V}$ appears, providing further evidence of the formation of PAMDAN-iodine complexes. ${ }^{16}$ The above results agree with that in literature, so precipitation-dissolution mechanism for the oxidation process at bare $\mathrm{Pt}$ electrode is still valid at PAMDAN/Pt modified electrodes. ${ }^{13-17}$ For thicker film (20 scans), as shown in Figure 6 , the $1^{\text {st }}$ oxidation peak disappears and only the $2^{\text {nd }}$ one appears at $0.58 \mathrm{~V}$ with decrease in its current. The broad cathodic peak appears at $0.28 \mathrm{~V}$ with some shoulders in it. This is due to the presence of thick PAMDAN film on Pt electrode which hinders the diffusion of iodide ions to be oxidized at $\mathrm{Pt}$ surface. ${ }^{13-17,21-24}$ It was found that the iodide ion concentration affects the redox response of the oxidation process. Figure 7 shows the cyclic voltamograms of the $0.01 \mathrm{M}$ and $0.05 \mathrm{M} \mathrm{KI}$. It illustrates the dependence of the redox response on the $\mathrm{I}^{-}$ion concentration. At this point further study will be needed to show the availability of use PAMDAN/Pt modified electrode as a sensor for detection and determination of $\mathrm{I}^{-}$ion in a variety of fields such as food, ${ }^{25}$ environmental and industrial applications $^{11,26,27}$ and also as a sensor for biological

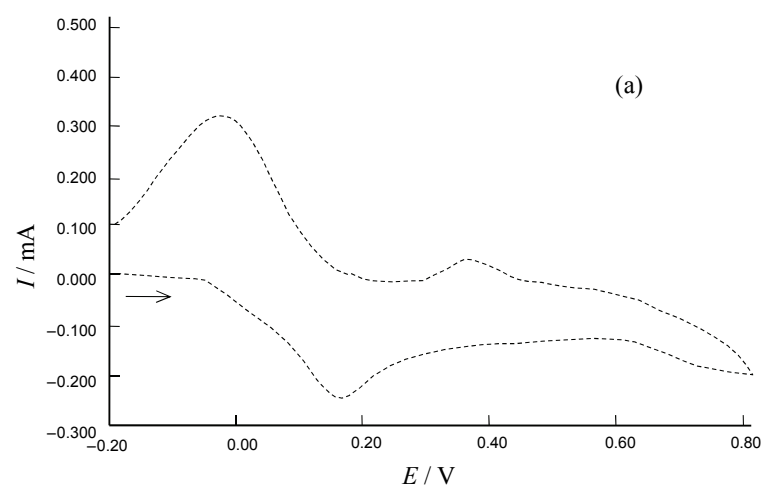

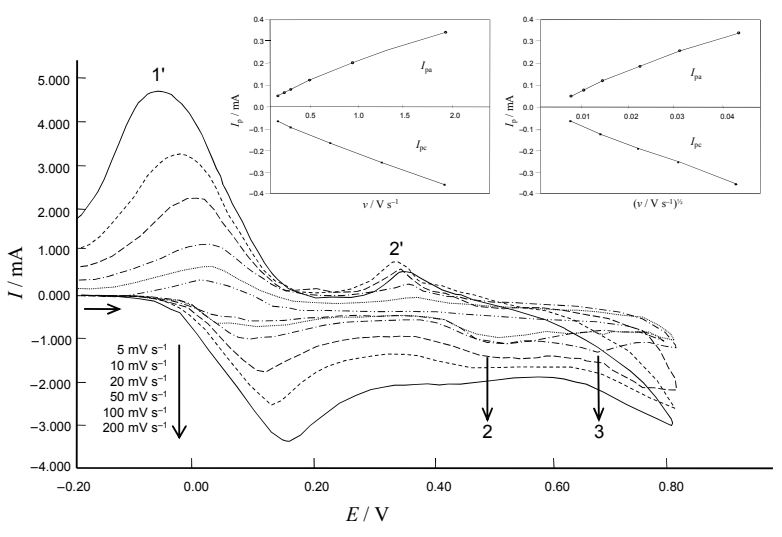

Figure 5. Cyclic voltamograms of the PAMDAN/Pt modified electrode in $0.1 \mathrm{M} \mathrm{HClO}_{4}$ containing $0.1 \mathrm{M} \mathrm{KI}$ at different scan rates: $v=5 \mathrm{mV} \mathrm{s}^{-1}$ (line dot line), $10 \mathrm{mV} \mathrm{s}^{-1}$ (broken line), $20 \mathrm{mV} \mathrm{s}^{-1}$ (full line), $50 \mathrm{mV} \mathrm{s}^{-1}$ (dots), $100 \mathrm{mV} \mathrm{s}^{-1}$ (broken line) and $200 \mathrm{mV} \mathrm{s}^{-1}$ (full line). The inset illustrates the relationships between $I_{\mathrm{p}, \mathrm{a}}, I_{\mathrm{p}, \mathrm{c}}-$ scan rate and the square root of scan rate. The modified electrode was prepared as mentioned in the text.

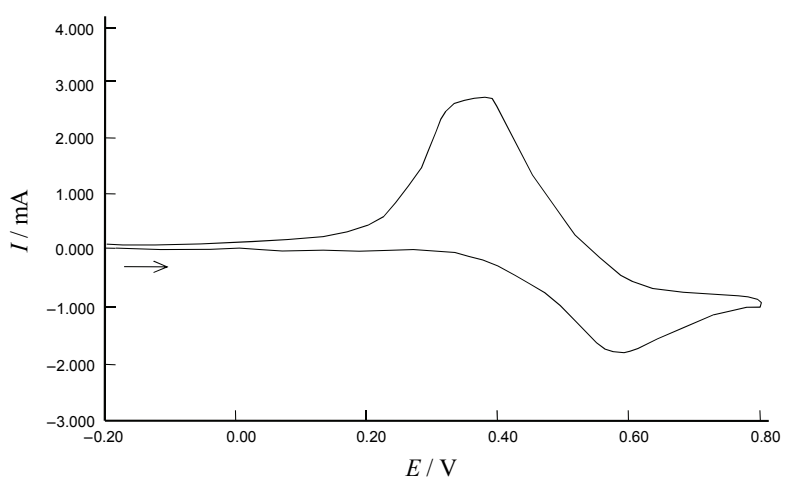

Figure 6. Cyclic voltamogram of the PAMDAN/Pt modified electrode in $0.1 \mathrm{M} \mathrm{HClO}_{4}$ containing $0.1 \mathrm{M} \mathrm{KI}$ at $v=50 \mathrm{mV} \mathrm{s}^{-1}$. The modified electrode was prepared by 20 cycles and the other conditions are as mentioned in the text.

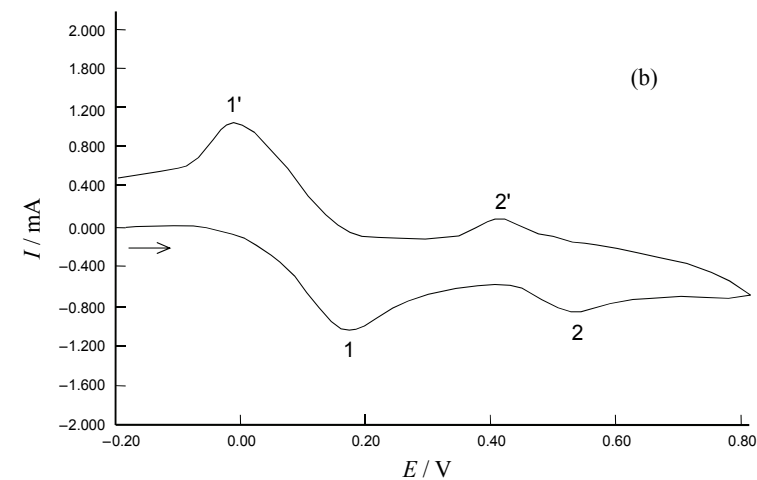

Figure 7. Cyclic voltamogram of the PAMDAN/Pt modified electrode in $0.1 \mathrm{M} \mathrm{HClO}_{4}$ containing $0.01 \mathrm{M} \mathrm{KI}$ (a) and $0.05 \mathrm{M} \mathrm{KI}$ (b) at $v=100 \mathrm{mV} \mathrm{s}^{-1}$. The modified electrode was prepared as mentioned in the text. 


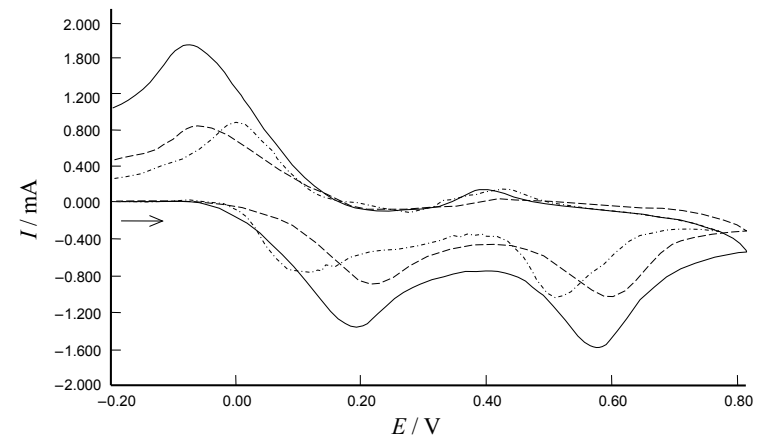

Figure 8. Cyclic voltamograms of the PAMDAN/Pt modified electrode in different concentrations of $\mathrm{HClO}_{4}: 0.01 \mathrm{M}(---)$,

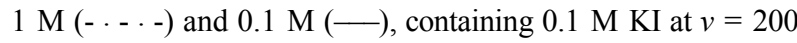
$\mathrm{mV} \mathrm{s}^{-1}$. The modified electrode was prepared as mentioned in the text.

systems. ${ }^{12}$ The effect of acid concentration was studied also, as shown in Figure 8. It was found that the redox peak height increase with increasing the acid concentration from $0.01 \mathrm{M}$ to $0.1 \mathrm{M}$. This is due to more protonated $\mathrm{N}^{+}$species, which make their contribution to the interaction of iodide species with AMDAN chain to increase. For higher concentration, at $1 \mathrm{M}$, more $\mathrm{N}$ atoms in the PAMDAN main chain are protonated, hence the interaction between iodide ion species and protonated $\mathrm{N}$ atoms must be enhanced, but in contrast, the higher concentration of $\mathrm{ClO}_{4}^{-}$anion depress the interaction process ${ }^{21,23,24}$ resulting in the decrease in peak current at high concentration of acid, as shown in Figure 8.

The stability of the PAMDAN/Pt modified electrode was studied. It was found that the modified electrode exhibits a good stability for $\mathrm{I}^{-}$ion over a period of several days retaining approximately $95 \%$ of its initial response to the oxidation of $\mathrm{I}^{-}$ion, making them an excellent candidate for application in electrocatalysis or as sensors.

\section{CONCLUSION}

The present work aims to discuss the electro catalytic oxidation of iodide ion on the PAMDAN/Pt modified electrode in aqueous acidic KI solution, suggesting that the precipitation-dissolution mechanism for this oxidation process at a bare Pt electrode is still valid at PAMDAN/Pt modified electrodes. In addition, the redox response depends on the experimental conditions such as scan rate, film thickness, iodide ion concentration and the acid concentration in the supporting electrolyte. A method for the use of PAMDAN/Pt modified electrode for detection and determination of iodide ion by cyclic voltammetry needs further study.

\section{REFERENCES}

1. V. S. Vasantha and S-M. Chen, J. Electroanal. Chem. 592 (2006) 77-87.

2. E. A. Khudaish and A. A. Al Farsi, Talanta 80 (2010) 1919-1925.

3. A. Salimi and K. Abdi, Talanta 63 (2004) 475-483.

4. H-W. Chu, R. Thangamuthu, and S-M. Chen, Electrochim. Acta 53 (2008) 2862-2869.

5. A. A. Hathoot, M. Abdel Kader, and M. Abdel Azzem, Int. J. Electrochem. Sci. 4 (2009) 208-222.

6. B. Nalini and S. S. Narayanan, Anal. Chim. Acta 405 (2000) 93-97.

7. W. Chen, J. Tang, H-J. Cheng, and X-H. Xia, Talanta 80 (2009) 539-543.

8. A. A. Hathoot, D. Sherif, and M. Abdel Azzem, Croat. Chem. Acta 83 (2010) 143-149.

9. R. Noufi, A. J. Nozik, J. White, and L. F. Warren, J. Electrochem. Soc. 129 (1982) 2261-2265.

10. N. N. Greenwood and A. Earnshaw, Chemistry of the Elements, Pergamon, Oxford, 1984.

11. T. Fujiwara, I. U. Mohammadzai, H. Inoue, and T. Kumamaru, Analyst 125 (2000) 759-763.

12. M. P. Arena, M. D. Porter, and J. S. Fritz, Anal. Chem. 74 (2002) 185-190.

13. S. Swathirajan and S. Bruckenstein, J. Electroanal. Chem. 112 (1980) 25-38.

14. S. Swathirajan and S. Bruckenstein, J. Electroanal. Chem. $\mathbf{1 4 3}$ (1983) $167-178$

15. X. Liao, K. Tanno, and F. Kurosawa, J. Electroanal. Chem. 239 (1988) 149-159.

16. H. Tang, A. Kitani, and M. Shiotani, J. Appl. Electrochem. 26 (1996) 36-44.

17. G. Mengoli, M. M. Musiani, D. Pletcher, and S. Valcher, J. Appl. Electrochem. 17 (1987) 525-531.

18. H. A. Abd El-Rahman, A. A. Hathoot, M. E. Bagoury, and M. Abdel Azzem, J. Electrochem. Soc. 147 (2000) 242-247.

19. U. S. Yousef, A. A. Hathoot, and M. Abdel Azzem, Europ. Polymer J. 37 (2001) 1267-1276.

20. A. A.Hathoot, A. E.Taha, and M. Abdel Azzem, Bull. Fac. Sci. Alex. Uni. 34 (2004) 53-65.

21. L. Tian, L. Liu, L. Chen, N. Lu, and H. Xu, Talanta 66 (2005) 130-135.

22. J. Yano, Bull. Chem. Soc. Jpn. 64 (1991) 1490-1496.

23. Y. A. Yaraliyev, Electrochim. Acta 29 (1984) 1213-1214.

24. H. Tang, A. Kitani, and M. Shiotani, J. Appl. Electrochem. 26 (1996) 45-50.

25. T. Bejerano and E. Gileadi, J. Electroanal. Chem. 82 (1977) 209-225.

26. S. X. Yang, S. J. Fu, and M. L. Wang, Anal. Chem. 63 (1991) 2970-1973.

27. S. S. M. Hassan and S. A. M. Marzouk, Electroanalysis 5 (1993) 855-861. 